\title{
Memórias de uma vida passada?
}

\section{Memories of a previous life?}

\author{
ERLENDUR HARALDSSON ${ }^{1}$ \\ IFaculdade de Psicologia, Universidade da Islândia (University of Iceland), Islândia.
}

Tradução: Cristiane Schumann Silva Curcio

Revisão da tradução: Alexander Moreira-Almeida

Recebido: 16/1/2014 - Aceito: 16/1/2014

\section{Resumo}

Contexto: Há crianças que alegam ter memórias de uma vida passada. Se essas supostas memórias puderem ser verificadas, elas poderão ser bastante relevantes para a questão da relação mente-cérebro. Elas poderão indicar que a memória não está apenas armazenada no cérebro e que a mente pode existir sem um cérebro e ainda assim reter algumas de suas memórias. Essas possibilidades são contrárias ao que atualmente se sabe sobre memória e sua dependência do funcionamento cerebral. Objetivos: Testar se um pesquisador independente obteria achados comparáveis aos de Stevenson (Universidade da Virgínia) que publicou um grande números desses casos. Métodos: Entrevistar as crianças que faziam afirmações consistentes sobre uma vida passada e as pessoas que haviam testemunhado as crianças fazerem essas declarações. Três estudos psicológicos compararam crianças com e sem alegadas memórias de uma vida passada. Resultados: Em dois dos três casos apresentados, foi encontrada uma pessoa falecida cujas características eram compatíveis com as afirmações das crianças sobre uma vida anterior. Psicologicamente, essas crianças diferem das outras crianças, mostrando sinais de Transtorno de Estresse Pós-Traumático, provavelmente por causa das alegadas lembranças de como elas morreram em acidentes ou foram assassinadas. Conclusões: As características dos casos de "memória de vida passada" fazem com que estas sejam relevantes para a questão da relação mente-cérebro.

Haraldsson E / Rev Psiq Clín. 2014;41(1):21-6

Palavras-chave: Memória, criança, religião e psicologia, transtornos de estresse pós-traumáticos, reencarnação, parapsicologia.

\begin{abstract}
Background: Children are sometimes found who claim to have memories of a past life. If such alleged memories can be verified they may prove relevant for the question of the mind-brain relationship. They may indicate that memory is not only stored in the brain and that mind can exist without a brain and still retain some of its memories. These possibilities are contrary to what is presently known about memory and its dependence on brain functioning. Objectives: Were to test if an independent investigator comes up with comparable findings as Stevenson of University of Virginia who has published a great number of such cases. Methods: Consisted of interviewing children who make consistent statements about a previous life and persons who have witnessed them making such statements. Three psychological studies compared children with and without past-life memories. Results: In two of three presented cases a deceased person was found who fitted the child's statements about the previous life. Psychologically these children differ from other children, showing signs of Post-Traumatic Stress Disorder, likely because by remembering how they died in accidents or were killed. Discussion: The features of "past-life memory" cases make them relevant for question of the mind-brain relationship.
\end{abstract}

Haraldsson E / Rev Psiq Clín. 2014;41(1):21-6

Keywords: Memory, child, religion and psychology, post-traumatic stress disorders, reincarnation, parapsychology.

\section{Introdução}

Em muitos países, podemos encontrar crianças que dizem se lembrar de episódios de uma vida passada. Se essas alegadas memórias forem específicas o suficiente e puderem ser verificadas, elas poderão indicar que memórias não são armazenadas apenas no cérebro e que a mente pode existir sem um cérebro e ainda reter algumas de suas memórias. Essas possibilidades são contrárias ao que é atualmente conhecido sobre memória e sua dependência do funcionamento cerebral.

Há meio século o professor Ian Stevenson, da Universidade da Virginia, conduziu os primeiros estudos de casos do tipo reencarnação (cases of the reincarnation type $)^{1,2}$. Desde então, mais de 2.500 casos têm sido registrados e investigados ao redor do mundo. Nos anos 1980 , Stevenson perguntou ao autor desse texto se ele estaria disposto a fazer um estudo independente sobre alguns casos. Será que este encontraria características semelhantes às relatadas por Stevenson?

$\mathrm{O}$ autor investigou mais de sessenta casos no Sri Lanka ${ }^{3-5}$, majoritariamente encontrados em famílias budistas e alguns casos entre cristãos e muçulmanos, e trinta casos no Líbano que foram encontrados na comunidade Drusa onde a crença na reencarnação é bastante disseminada ${ }^{6,7}$. Alguns poucos casos foram investigados em outros países. Três estudos psicológicos compararam crianças que relataram alegadas memórias de vidas passadas com pares que não relataram essas memórias ${ }^{8-10}$.

O conteúdo dessas alegadas memórias (que por questão de brevidade serão, de agora em diante, referidas apenas como memórias) variou amplamente e a maioria das crianças falou sobre como elas morreram violentamente por meio de acidentes, assassinatos ou atos de guerra. Elas falavam dos eventos que as levaram às suas mortes, das pessoas que elas conheceram e de onde elas teriam vivido. Diziam sobre eventos que ocorreram na área ou em áreas próximas de onde viviam. Muitas sofriam de fobias que elas associavam com o modo de morte da vida passada.

A maioria das crianças começa a falar de uma vida passada assim que elas são capazes de falar, em torno dos dois anos e meio de idade. O número de afirmações que elas fazem varia, e é, em média, por volta de vinte. A maioria delas para de falar sobre sua vida passada por volta da época em que elas vão para a escola. Com frequência essas crianças desejam encontrar seus lares anteriores e algumas vezes dizem onde ele é. Amiúde dizem que suas mães atuais não são suas mães reais. Ocasionalmente, elas revelam conhecimentos ou habilidades, sem que saiba como elas os teriam aprendido. Algumas têm marcas de nascença ou deformidades que elas correlacionam 
com o modo como morreram na vida anterior. Estudos psicológicos mostram características que revelam um Transtorno de Estresse Póstraumático (TEPT), mas não em todas as crianças9. Uma provável explicação para o TEPT seria as memórias de uma morte violenta, o que preocupa até $75 \%$ dessas crianças no início da infância.

\section{Métodos}

O principal método de investigação é entrevistar pessoas que testemunharam de primeira mão os relatos da criança sobre a vida passada, tais como pais, irmãos, parentes, colegas, bem como a própria criança. Isso é feito para averiguar quais afirmações a criança fez, bem como a consistência dessas afirmações em diversas ocasiões. $\mathrm{O}$ segundo passo é descartar que a criança esteja falando sobre eventos que ela aprendeu em seu ambiente. Se este não é o caso e há um razoável consenso sobre as afirmações, então o caso é considerado merecedor de uma investigação mais profunda. É importante entrevistar a principal testemunha novamente após algum tempo para testar a confiabilidade de seu testemunho.

A próxima questão é rastrear se alguma pessoa falecida possuía eventos de vida correspondentes às afirmações feitas pela criança. Com frequência uma pessoa com as características descritas pela criança é encontrada. É necessário checar se tais correspondências existem de fato. A família dessa pessoa é entrevistada e documentos relevantes são obtidos, tais como certidões de nascimento e de óbito, laudos de necropsia etc. A seguir, é apresentada uma revisão de três casos.

\section{0 caso de Thusita Silva}

Este caso é particularmente interessante porque as afirmações da menina foram registradas por nós antes de qualquer pessoa e os eventos de vida que correspondiam às afirmações de Thusita foram encontrados. Encontramos Thusita Silva (pseudônimo) em 1991. Ela tinha 8 anos de idade e vivia em precárias condições perto da cidade de Panadura, no sul de Colombo, Sri Lanka. Thusita havia falado sobre sua vida passada em Akuressa por um certo tempo (população de aproximadamente 20.000 habitantes), quando seu irmão bem mais velho foi até lá para checar a história da irmã. Ele não conseguiu verificar os fatos e repreendeu a irmã. Nenhuma outra tentativa foi feita pela família para tentar resolver o caso. Alguns anos se passaram quando soubemos do caso e entrevistamos a menina, sua mãe e sua avó. Nessa época, ela havia se esquecido de algumas de suas memórias anteriores. De acordo com sua mãe e sua avó, quando ela tinha 2 anos e meio de idade, ela disse: "Eu sou de Akuressa, o nome do meu pai é Jeedin Nanayakkara". Ela teria vivido perto de um rio e, quando estava atravessando uma ponte estreita, caiu no rio e morreu afogada. Na ocasião, ela estava grávida. Ela teria um marido e a casa em que ela morava seria maior do que a casa atual. Para a lista completa das afirmações de Thusita, veja a tabela 1.

Durante uma visita a Akuressa encontramos uma família Nanayakkara que vivia perto de uma ponte suspensa para pedestres. Essa família nos contou que sua nora estava atravessando a ponte em 1973 quando caiu da ponte e se afogou. $\mathrm{O}$ marido dela estava com ela, pulou no rio para salvá-la, mas também quase se afogou. No escritório do médico legista, havia um arquivo sobre o caso. Chandra Nanayakkara (nascida em Abeygunasekera) morreu em dezembro de 1973 "por afogamento após a ingestão de água, quando ela caiu da ponte suspensa no rio Nilwala”. Ela tinha 27 anos de idade, estava grávida de sete meses e estava com o marido quando o acidente ocorreu.

Dezessete das vinte e oito afirmações de Thusita correspondiam à vida de Chandra Nanayakkara; 7 eram incorretas e 4, indeterminadas. Todas as afirmações de Thusita relatando o modo de morte correspondiam (a ponte suspensa, a queda no rio, a gravidez e que o marido estava com ela). O nome de seu pai não era Jeedin Nanayakkara, mas o do sogro era Edwin Nanayakkara. As mulheres em Sri Lanka geralmente se referem ao sogro como pai. As afirmações incorretas foram sobre a cor de sua bicicleta, que ela teria trabalhado em um hospital (a melhor amiga dela trabalhava) e que seu marido era carteiro (o irmão dela era), mas ele era motorista de ônibus. Outras afirmações eram gerais demais para serem valorizadas ${ }^{11}$.
A família de Thusita alegou não ter tido nenhum contato anterior com Akuressa e que nenhum deles tinha estado lá quando Thusita falou sobre sua vida anterior. Akuressa fica a aproximadamente 50 $\mathrm{km}$ do lugar de nascimento de Thusita, que é em Elpitiya, de onde ela se mudou para Panadura, onde a encontramos.

Casos em que as afirmações da criança foram registradas antes que qualquer pessoa anterior fosse identificada são de grande importância, uma vez que, nesses casos, se pode ter a certeza de que as afirmações da criança não estão contaminadas. Outros casos recentes desse tipo são os casos de Chatura Karunaratne ${ }^{5}$, Dilukshi Nissanka ${ }^{3}$, e um caso investigado por Keil e Tucker ${ }^{12}$.

Tabela 1. Afirmações de Thusita Silva sobre sua vida passada. As afirmações que conferem com as da vida de Chandra Nanayakkara estão marcadas com + e aquelas que não conferem estão marcadas com - e as indeterminadas com?

\begin{tabular}{|l|l|l|}
\hline 1 & Eu vivi em Akuressa & + \\
\hline 2 & O nome do meu pai era Jeedin & - \\
\hline 3 & (O nome do meu pai era) Nanayakkara & + \\
\hline 4 & Rio ou córrego perto & + \\
\hline 5 & A ponte suspensa (wel palama) quebrou & + \\
\hline 6 & Eu caí no rio & + \\
\hline 7 & Eu me afoguei & + \\
\hline 8 & Eu estava grávida quando afoguei & + \\
\hline 9 & Eu tinha um marido & + \\
\hline 10 & Nossa casa era maior do que a nossa casa atual & + \\
\hline 11 & As paredes eram coloridas & + \\
\hline 12 & Eu tinha uma sobrinha & - \\
\hline 13 & Meu pai anterior era chamado appa (o pai atual dada) & $?$ \\
\hline 14 & Eu tinha uma bicicleta & + \\
\hline 15 & A bicicleta era amarela & - \\
\hline 16 & Eu ia para o trabalho de bicicleta & - \\
\hline 17 & Eu pedalava a bicicleta sozinha & + \\
\hline 18 & Eu trabalhava em um hospital & - \\
\hline 19 & Eu vestia um uniforme branco com chapéu e sapatos & - \\
\hline 20 & O hospital era um pouco distante de casa & + \\
\hline 21 & Mamãe usava túnica & $?$ \\
\hline 22 & Mamãe tinha uma máquina de costura & + \\
\hline 23 & Eu tinha duas túnicas listradas & + \\
\hline Itens relatados para Tissa Jayawardane (assistente do autor no Sri Lanka) mas \\
não para Erlendur Haraldsson & + \\
\hline 24 & Grande portão na antiga casa & + \\
\hline 25 & Meu marido pulou no rio para me salvar & + \\
\hline 26 & Meu marido era carteiro & \\
\hline 27 & Nós tínhamos um carro & + \\
\hline 28 & Eu tinha um sutiã & + \\
\hline $\mathbf{1 7}$ afirmações corretas (+), 7 afirmações incorretas (-) e 4 \\
indeterminadas (?) & + \\
\hline & & + \\
\hline
\end{tabular}

\section{O caso de Prethiba Gunawardana}

Prethiba Gunawardana, um garoto forte e saudável, tinha quatro anos de idade quando o encontramos com a mãe em 1989, em sua casa, no subúrbio de Colombo, Sri Lanka. Apenas depois de convencermos a mãe de Prethiba de que não iríamos divulgar o caso no Sri Lanka foi que ela se dispôs a conversar conosco. Prethiba fez suas primeiras afirmações sobre uma vida passada após ele sofrer uma crise febril por uma semana, quando ele tinha um pouco mais que 2 anos de idade. Depois disso, frequentemente ele falava sobre suas memórias. Ele conversou conosco sem timidez e insistiu que suas memórias eram de uma vida anterior.

Prethiba dizia que ele viveu em Kandy (usando o nome Cingalês Maha Nuwara), a principal cidade do centro de Sri Lanka. Ele disse que seu nome anterior era Santha Megahathenne e que ele vivera 
no número 28 da estrada de Pilagoda. Seu carro teria pegado fogo, ele teria queimado sua perna e mão direitas e sua boca. Havia sido levado para um hospital e, então, ele "veio para cá" (morreu). A mãe dele nos contou que ele frequentemente mencionava dois nomes: um irmão mais velho chamado Samantha e uma irmã mais velha chamada Seetha. De acordo com seu pai, mais tarde Prethiba com frequência dizia que queria vê-los. Ele falava mais sobre pessoas do que sobre eventos. Suas afirmações estão listadas na tabela 2. Prethiba não apresentava traços comportamentais incomuns que pareciam relacionados às suas afirmações.

Tabela 2. Afirmações feitas por Pretiba Gunawardana sobre sua vida passada

\begin{tabular}{|l|}
\hline 1. Frequentes menções a Samantha aya (irmão mais velho) \\
\hline 2. Frequentes menções a Seetha akka (irmã mais velha) \\
\hline 3. A irmã mais velha era casada \\
\hline 4. Menções a Loku aya and Loku akka (grande/mais velho) \\
\hline 5. Menções Dhamman Sadhu, um parente do irmão do pai \\
\hline 6. Eles tinham um carro e um ônibus \\
\hline 7. Seu carro foi queimado (muita fumaça) com ele dentro \\
\hline 8. A mão direita, a perna e a boca foram queimados \\
\hline 9. Foi internado no hospital Nuwara e emplastros foram colocados em seu corpo \\
\hline 10. Depois disso ele veio para este lugar (morreu e nasceu aqui) \\
\hline 11. Ele já esteve na Îndia e em um templo Hindu (kovil) \\
\hline 12. Ele tinha um passaporte \\
\hline 13. Mencionou o nome Natapati (Nathapathi), visitou Natapati Devalaya (kovil) \\
enquanto esteve na Índia \\
\hline 14. Trouxe da Índia alguns presentes para sua mãe (saris e botões) \\
\hline 15. Ele morou no número 28 da estrada Pilagoda em Nuwara (Kandy) \\
\hline 16. Ele morava no andar de cima da casa \\
\hline 17. Seu pai era idoso \\
\hline 18. Seu pai tinha um carro \\
\hline 19. Seu pai usava óculos \\
\hline 20. Seu pai tinha ido ao exterior e retornou \\
\hline 21. Mencionou uma briga entre uma cobra e um lagarto \\
\hline 22. Ele tinha uma namorada mas não queria se casar com ela \\
\hline 23. Eles tinham uma casa com terreno em torno dela \\
\hline 24. Ele tinha um tio \\
\hline 25. Eles tinham paddyfields (plantações úmidas de arroz) \\
\hline 26. Balansena trabalhava nos paddyfields \\
\hline 27. Existia um templo perto de casa \\
\hline 28. Obras de arte de elefantes no templo \\
\hline 29. Ele participava da escola dominical no templo \\
\hline 30. Eles tinham um refrigerador \\
\hline 31. Eles tinham um pettagama (caixa grande de madeira) \\
\hline 32. Ele tinha um bom relógio de pulso \\
\hline 33. Mencionou Punchi Amma (irmã mais nova de sua mãe) \\
\hline 34. O marido de Punchi Amma tinha um caminhão e era empresário \\
\hline 35. O nome dele era Santha Megahathenne \\
\hline 36. Ele tinha um amigo chamado Asanga \\
\hline 37. Bandara também morava lá \\
\hline 38. Ele usava calças \\
\hline 39. Ele frequentava a escola \\
\hline 40. Eles tinham uma conta bancária \\
\hline 41. Seu irmão anterior parecia com o irmão de sua mãe atual \\
\hline
\end{tabular}

Quando perguntamos ao garoto se ele gostaria de ir até Kandy, ele rapidamente respondeu que sim. Ele disse que seria capaz de encontrar a sua casa, mas quando perguntamos se ele sabia exatamente onde ela ficava, ele disse que não. O pai dele não desejava procurar pela personalidade prévia e a mãe partilhava de um medo comum que as mães dessas crianças têm, que é de perder o seu filho para a família anterior, se ela fosse encontrada. O menino também tinha dito que queria ir para Kandy para recolher suas coisas.

Autoridades do serviço postal nos disseram que não havia uma estrada Pilagoda na cidade de Kandy, nem qualquer aldeia ou área com esse nome no distrito de Kandy. Também questionamos sobre o nome Megahathenne que Prethiba deu como seu antigo nome de família. Alguns Cingaleses usam o nome da vila de onde eles vêm como um sobrenome. Uma aldeia com o nome de Megahathenne existe perto de Galagedara a cerca de 15 milhas de distância de Kandy. Consultas lá não renderam nenhuma informação sobre qualquer pessoa com as características descritas por Prethiba, nem houve qualquer estrada Pilagoda encontrada naquela aldeia, nem o sobrenome Megahathenne foi encontrado na lista telefônica de Kandy de 1975.

Os pais aceitaram a nossa proposta de levar o menino até Kandy. A viagem de três horas passa por muitas vilas e cidades. À medida que nos aproximávamos da ponte sobre o rio Mahaveli, onde do lado oposto era a cidade de Kandy, o menino tornava-se bastante animado. Ele espontaneamente disse: "Ali está Maha Nuwara" (nome cingalês para Kandy) e, enquanto atravessávamos a ponte (uma das poucas no caminho) sobre o rio Mahaveli, ele corretamente observou: "Este é o Mahaveli Ganga" (ganga = rio). Nem nós, nem os seus pais havíamos mencionado esse nome, nem dado qualquer indicação de que estávamos prestes a entrar na cidade de Kandy. Além dessas duas afirmações, não houve resposta ou comentário de Prethiba para indicar qualquer reconhecimento ou conhecimento da área. Dirigimos por um tempo dentro de Kandy, mas Prethiba não conseguiu nos dizer como encontrar sua antiga casa e não expressou nenhum desejo de ver algum determinado ponto, embora ele tivesse gostado da viagem.

Investigações em Kandy e Megahathenne não conseguiram identificar uma pessoa que correspondesse às afirmações de Prethiba. Era impossível para nós procurar nas milhares de admissões anuais ao hospital de Kandy, na esperança de encontrar o nome de Santha Megahathenne. Sem revelar a identidade do rapaz, as principais características do caso foram publicadas com a permissão dos pais em uma entrevista com o autor deste texto em 11 de dezembro de 1990 , no jornal Dinamina, um jornal cingalês de grande circulação e em sua edição em inglês, o Daily News. Nenhuma resposta veio dos leitores. Apesar de nossos esforços, nenhuma pessoa que correspondesse às descrições de Prethiba foi encontrada.

\section{O caso de Wael Kiwan}

Este caso é do Líbano7 ${ }^{7}$ Ele apresenta algumas das limitações comumente encontradas nesses casos, mas também contém algumas afirmações altamente específicas feitas pelo sujeito, o que nos permitiu identificar uma pessoa falecida cujos eventos de vida se assemelhavam muito àqueles que o menino havia descrito.

Wael Kiwan era um garoto saudável e maduro quando o encontramos em sua vila a uns $70 \mathrm{~km}$ a leste de Beirute. Seus pais disseram que desde muito pequeno ele começou a dizer que seu nome era Rabih, que ele já tinha sido uma pessoa crescida, possuía outros pais em Beirute e que queria encontrá-los. Havia outras afirmações: "Existia uma casa com um telhado de tijolo vermelho" e "ele morava na seção de Jal al Bahr de Beirute" (ou seja, à beira-mar) e perto da casa de Allah Wa Akbar (i.e., uma mesquita). Ele falava muito sobre o mar e sobre um barco. Ele desenhava o timão de um barco e dizia: "Eu costumava guiar" e ele fazia um movimento circular com suas mãos para mostrar como ele manobrava o timão. Ele disse que havia uma sacada, de onde ele costumava pular para ir para a rua. Ele fez a declaração altamente específica de que ele tinha duas casas, uma em Beirute e uma outra em que, para ir, ele teve que viajar de avião.

Ele fez o que algumas crianças que falam de uma vida anterior fazem e disse à sua mãe: "Minha mãe [anterior] é mais bonita do que você". Muitas vezes ele repetiu a história sobre a sua morte: era pôr do sol, ele viu pessoas que vieram em sua direção e atiraram nele. Wael também disse: "Se você encontrar a minha família, não lhes 
diga que Rabih morreu, porque eles vão chorar”. Na tabela 3 estão listadas as afirmações que ele, de acordo com seus pais, fizera antes de eles efetivamente começarem a procurar por uma pessoa falecida que se ajustava às características que Wael descrevera.

Tabela 3. Afirmações feitas por Wael Kiwan de acordo com seus pais. As afirmações que conferem com a vida de Rabih estão marcadas com +, as que não conferem com - e as indeterminadas com?

\begin{tabular}{|l|l|}
\hline 1. Meu nome era Rabih & + \\
\hline 2. Eu era grande (não pequeno) & + \\
\hline 3. Eu tinha pais. Eles não estão aqui, estão em Beirute & + \\
\hline 4. Minha casa é em Beirute próxima ao mar & + \\
\hline 5. Minha casa é perto de Allah Wa Akbar (mesquita) & + \\
\hline 6. Existia uma casa com o telhado vermelho & + \\
\hline 7. Era pôr do sol e eu vi umas pessoas vindo, elas atiraram em mim & - \\
\hline 8. Um grupo de pessoas me chutou e me bateu até que eu não senti mais nada & - \\
\hline 9. Eu estava frequentemente em um barco no mar & + \\
\hline 10. Eu costumava guiar o barco com um timão & $?$ \\
\hline 11. Eu podia ir a pé da minha casa até o mar & + \\
\hline 12. Minha casa era em Jal al Bahr & + \\
\hline $\begin{array}{l}\text { 13. Eu tinha 2 casas, uma em Beirute e uma outra para a qual eu tinha que } \\
\text { ir de avião }\end{array}$ & + \\
\hline 14. Nós tínhamos uma sacada & + \\
\hline 15. Eu costumava pular da sacada para a rua & + \\
\hline 16. Eu costumava jogar um ferro para parar o barco (reportado apenas pela \\
tia) & $?$ \\
\hline 17. Minha mãe anterior era mais bonita que você & $?$ \\
\hline 12 afirmações confirmadas, 2 afirmações incorretas e 3 indeterminadas \\
\hline
\end{tabular}

Certa vez, seu pai, com esposa e filhos, sentou-se com Wael e mencionou muitos nomes de família na esperança de que ele pudesse reconhecer algum deles. Quando mencionou o nome Assaf, ele disse que era o nome de sua família anterior. Assaf é um nome bastante comum entre drusos, cristãos e muçulmanos.

Wael muitas vezes pediu ao pai que encontrasse a sua casa anterior quando este ia para Beirute a negócios e ele ficava chateado quando seu pai retornava sem sequer ter tentado. Finalmente, seu pai contou a um amigo druso em Beirute, Sami Zhairi, o que Wael estava dizendo e esse amigo prometeu investigar as informações entre os drusos. Ele descobriu que um Rabih Assaf havia existido, que ele morava perto do mar, no distrito de Jal-al-Bahr, cuja vida parecia se encaixar nas afirmações de Wael.

Wael foi levado pelo seu pai até Beirute. Acompanhado de Sami Zhairi, eles foram até a casa na região de Jal-al-Bahr. Wael saiu correndo, à frente do grupo, em direção à casa, adentrou o apartamento no piso térreo onde ele viu um retrato na parede e disse: "Esta é a minha foto". Aquela era uma foto de Rabih Assaf. No apartamento estava Raja Assaf, irmão do falecido Rabih (a mãe deles, Munira, não estava em casa). Raja trouxe um álbum de fotos e pediu a Wael que identificasse as pessoas. De acordo com o pai de Wael, ele reconheceu o pai de Rabih, sua irmã e uma tia paterna. Quando eles deixaram a casa e estavam retornando, Wael disse a seu pai que agora ele estava relaxado, pois havia encontrado sua casa anterior. Visitas ocasionais aconteceram e as famílias mantiveram contato através dos anos. Após o encontro com a família Assaf, Wael passou a falar menos sobre sua vida passada.

Munira Assaf estava em casa quando Wael foi até lá pela segunda vez. Ele parecia feliz por estar ali, mas ele não reconheceu a mãe de Rabih, a irmã gêmea dele, nem seu irmão. Munira não se recordou que ele reconheceu qualquer fotografia, somente que ele disse: "sim, sim". Ela quis dizer com isso que ele poderia conhecer as pessoas nas fotos.

Na primeira visita à casa da família Assaf, Wael foi para a porta dos fundos e perguntou sobre a casa com um telhado vermelho. Rabih havia crescido vendo essa casa com telhado vermelho da cozinha e do quintal do apartamento. Esta já havia sido demolida quando Wael foi visitá-los. Isto, mais do que qualquer outra coisa, fez com que a família acreditasse que Wael era Rabih renascido.

$\mathrm{O}$ apartamento de Munira Assaf é no piso térreo e tem uma sacada da qual é fácil para um garoto pular para a rua. Munira Assaf confirmou que Rabih frequentemente fazia isso. Wael repetidamente falava sobre um barco. A aproximadamente 30 metros da casa, e perto do fim de uma pequena rua, há um pequeno porto que atualmente está apertado entre casas e um grande arranha-céu. O marido e filhos de Munira não tinham barcos, mas amigos, parentes e vizinhos tinham, e Rabih costumava ir para o mar com eles. A maioria dos barcos eram barcos a remo e poucos tinham motor e leme. Esses pequenos barcos não tinham timão. No entanto, Rabih poderia ter feito algum passeio em um barco com um timão. Uma antiga mesquita fica a aproximadamente 100 metros de distância da casa de Rabih, na mesma rua do porto, e é a única mesquita na área de Jal-al-Bahr.

A assertiva de Wael sobre ter tido duas casas e que uma delas se tinha que ir de avião corresponde ao fato de que Rabih também havia morado nos Estados Unidos. A declaração: "Eu costumava jogar um ferro para parar o barco" só foi relatada a nós por Fadia, uma tia de Weal. O ferro que ele retratava ("hadideh", em árabe) provavelmente era uma âncora, uma palavra pouco provável de ser conhecida por alguém que vive longe do mar (como era o caso de Wael).

A mãe de Rabih esperava saber mais de Wael sobre a vida deste como Rabih, mas não conseguiu. No entanto, ela se convenceu e o aceitou, porém dizia também: "Nada vai trazer meu filho de volta".

A mãe de Wael nos disse que ele havia dado duas versões sobre a sua morte. A primeira foi a de que "eles" atiraram em sua cabeça. A segunda versão foi a de que um grupo de pessoas o chutou e bateu nele até que ele não resistiu (daí seus pais assumiram que ele tinha sido morto dessa forma).

Rabih morreu no sul de Pasadena, na Califórnia, em 1988. Ele havia se mudado para os Estados Unidos quando tinha 21 anos e estudou engenharia elétrica por dois anos. Durante o terceiro ano ele queria retornar à Beirute, mas não foi possível por causa da guerra civil do Líbano e, além disso, ele não tinha dinheiro nem para permanecer na Califórnia, nem para voltar para Beirute. Ele ficou deprimido, tentou suicídio tomando remédios, mas foi levado ao hospital e sobreviveu. Rabih mudou-se então para a casa de parentes distantes. Em 9 de janeiro de 1988 seu primo paterno, Abboud Assaf, o encontrou morto na garagem. Ele se enforcou. Isso foi verificado por meio de uma entrevista telefônica com o primo que não sabia da informação sobre um grupo tê-lo chutado e batido nele até a morte. A mãe de Rabih não sabia nada sobre esse incidente.

Um dos méritos desse caso é que as duas famílias moravam distantes uma da outra e eram completamente estranhas umas às outras. O principal ponto fraco desse caso é que as afirmações do sujeito não foram registradas antes das duas famílias terem se encontrado. Doze das dezessete afirmações de Wael correspondem a acontecimentos na vida de Rabih Assaf. Quatro itens não puderam ser confirmados nem refutados. A afirmação de que Rabih estaria no barco segurando um timão pode ter acontecido, mas certamente não foi um evento frequente em sua vida, porque as pequenas embarcações em que muitas vezes ele foi para o mar provavelmente não tinham timão.

Um item crucial que não se encaixa com a vida de Rabih é o modo como ele morreu. Essa é a única grande discrepância entre as afirmações de Wael e a vida de Rabih. Rabih cometeu suicídio, ao passo que Wael dizia que ele havia sido baleado. Se nos permitirmos alguma especulação e fantasia, a seguinte declaração de Wael pode ter algum significado: "Se você encontrar minha família, não lhes diga que Rabih morreu. Eles vão chorar". Isso poderia significar que ele teve alguma culpa sobre a forma de sua morte ou significar que ele não queria que se soubesse de seu suicídio? No que se refere ao enforcamento, é interessante falar sobre um "anúncio em sonho" que a mãe de Wael teve antes de seu nascimento; ela sonhou com um rapaz crescido que suava e respirava rapidamente e com dificuldade. Isso poderia estar relacionado ao enforcamento de Rabih?

O que corresponde bem é o nome Rabih, o nome da família Assaf, que ele tinha vivido perto do mar e que ia para o mar em 
barcos, que havia uma mesquita perto de sua casa, que ele pulava de sua sacada para a rua, que tinha vivido em dois lugares, a um dos quais ele tinha que viajar de avião, e a declaração que ele fez quando visitou pela primeira vez a família Assaf, que atrás de sua casa havia uma casa com um telhado vermelho. Muitas dessas afirmações são altamente específicas e pouco prováveis que sejam devidas ao acaso.

\section{Características psicológicas das crianças com memórias de vidas passadas}

As crianças que alegam memórias de vidas passadas se diferem psicologicamente das outras crianças? Dois estudos no Sri Lanka ${ }^{8,10} \mathrm{e}$ um no Líbano ${ }^{9}$ mostram que sim. Stevenson já havia percebido que elas frequentemente sofriam de fobias que muitas vezes pareciam relacionadas com suas memórias de vidas passadas. Essa observação foi verificada no Sri Lanka quando essas crianças eram comparadas a pares de mesma idade e contexto social. Mais tarde, esses achados foram replicados no Líbano. Resultados de dois itens do "Child Behavior Checklist" (CBCL) podem ser vistos na tabela 4 .

Tabela 4. Fobias e medos em sujeitos e controles em dois estudos combinados no Sri Lanka. Resultados de dois itens do Child Behavior Checklist

\begin{tabular}{|l|c|c|}
\hline & Sujeitos $(\mathrm{n}=57)$ & Controles $(\mathrm{n}=57)$ \\
\hline \multicolumn{2}{|c|}{ Tem medo de certas situações, lugares etc. } \\
\hline Frequentemente & 16 & 4 \\
\hline Algumas vezes & 6 & 18 \\
\hline Nunca & 21 & 33 \\
\hline É apreensivo, aflito ou ansioso demais \\
\hline Frequentemente & 12 & 2 \\
\hline Algumas vezes & 14 & 8 \\
\hline Nunca & 28 & 45 \\
\hline
\end{tabular}

O Child Behavior Checklist (CBCL) e o Child Dissociation Checklist (CDC) revelaram sintomas que caracterizam pacientes de TEPT com um trauma identificável, tais como fobias, medos, explosões de raiva e pesadelos. Tanto no Sri Lanka quanto no Líbano diferenças significativas no escore de problemas do CBCL e uma elevada pontuação no CDC indicam que crianças com memórias de vidas passadas são frequentemente traumatizadas (Tabela 5). O abuso infantil é uma causa potencial para esses problemas, porém não há sinais de abuso na breve vida das crianças investigadas. As causas para esses traumas poderiam ser encontradas nas imagens/ memórias da vida passada que elas reportaram? Isso se torna mais provável quando se considera que $77 \%$ da amostra do Líbano e $76 \%$ da amostra do Sri Lanka falam de experiências de uma morte súbita e violenta. A pontuação de problemas para o CBCL é maior em crianças que falam de morte violenta $(47,38, \mathrm{~N}=24)$ do que para aquelas que não o fazem $(36,00, \mathrm{~N}=6)$. A diferença significativa $(\mathrm{t}$ $=2,43, \mathrm{p}=0,03$, two-tailed ) pode dar peso ao argumento de TEPT.

Tabela 5. Diferenças psicológicas entre sujeitos e controle em três estudos no Sri Lanka e no Líbano

\begin{tabular}{|c|c|c|c|c|}
\hline \multicolumn{2}{|c|}{ Child Beh. Checklist problemas } & Sujeitos & Controle & Z-valor \\
\hline \multicolumn{2}{|c|}{ Primeiro estudo no Sri Lanka } & 41,33 & 26,77 & $3,73^{* *}$ \\
\hline \multicolumn{2}{|c|}{ Segundo estudo no Sri Lanka } & 34,5 & 17,54 & $3,80^{* *}$ \\
\hline \multicolumn{2}{|l|}{ Estudo no Líbano } & 45,10 & 27,70 & $3,73^{* *}$ \\
\hline \multicolumn{5}{|c|}{ Child Dissociation Checklist } \\
\hline \multicolumn{2}{|c|}{ Segundo estudo no Sri Lanka } & 6,59 & 1,69 & $3,80^{* *}$ \\
\hline \multicolumn{2}{|l|}{ Estudo no Líbano } & 1,47 & 23 & $2,61^{*}$ \\
\hline \multicolumn{5}{|c|}{ A correlação entre o CBCL e o CDC foi de $0,57(p<, 001)$} \\
\hline $\begin{array}{l}\text { Primeiro estudo no } \\
\text { Sri Lanka }\end{array}$ & Média idade & 9,39 anos & 12 meninos & 18 meninas \\
\hline $\begin{array}{l}\text { Segundo estudo no } \\
\text { Sri Lanka }\end{array}$ & -- & 7,83 & 14 meninos & 13 meninas \\
\hline Estudo no Líbano & -- & 10,62 & 19 meninos & 11 meninas \\
\hline
\end{tabular}

Essas crianças não fabulam mais do que as outras crianças, não são altamente sugestionáveis, não vivem em isolamento social ou em famílias com distúrbios de relacionamento e, aparentemente, não exibem o comportamento de busca de atenção $0^{8,9}$. Elas devaneiam ou se perdem em seus pensamentos mais frequentemente do que as outras crianças. Será que isso acontece porque elas estão preocupadas com suas imagens de vida passada? Nossos dados não são capazes de responder isso.

\section{Discussão}

Qualquer teoria explicativa desses casos precisa dar conta de três achados: memórias que foram verificadas como corretas na ausência de alguma outra explicação convencional, características psicológicas como fobias e TEPT, bem como as marcas de nascença que são encontradas em alguns casos e são compatíveis com as feridas de uma personalidade prévia. Os casos diferem amplamente e diferentes explicações podem ser aplicadas para diferentes casos. Explicações convencionais bem como explicações transcendentais/paranormais têm sido colocadas para explicar os casos. Elas variam de críticas ao modo como as investigações têm sido conduzidas, até a falha em considerar suficientemente como os casos são moldados culturalmente. Relatos publicados por Stevenson são muito detalhados e completos, por exemplo, os longos relatórios em quatro volumes de Stevenson sobre "Cases of the Reincarnation Type"13. É difícil imaginar como as influências culturais podem causar marcas de nascença que são formadas no embrião antes do nascimento da criança.

Outra crítica se refere à possibilidade de que as correspondências entre as afirmações das crianças e dos eventos na vida de certas pessoas falecidas possam ser devido ao acaso. Esta é uma crítica séria em vista dos muitos casos que permanecem sem solução, que chegam a $64 \%$ no Sri Lanka.

A interpretação do acaso é duvidosa para alguns dos casos mais impressionantes, pois contêm afirmações altamente específicas feitas pelas crianças. Essa interpretação também encontra dificuldades quando aplicada a casos de marcas de nascença, fobias e TEPT encontrados em um número considerável de crianças, sobre as quais não há relatos de terem sido expostas a situações de risco de vida.

Essas crianças são psiquicamente dotadas e capazes de captar fatos da vida de uma pessoa que viveu antes de elas nascerem? A interpretação encontra dificuldades ao tentar explicar os aspectos psicológicos e os casos de marcas de nascença. E por que essas crianças, que não se conhece ter qualquer dom psíquico (paranormal) específico, captariam no passado aspectos passados da vida de uma pessoa falecida específica?

Então, existem explicações transcendentais. A hipótese de possessão é algumas vezes mencionada, também em países onde a crença em reencarnação é dominante. A hipótese da reencarnação é mais amplamente aceita. Ela parece explicar mais facilmente as fobias, TEPT e as marcas de nascença. Há, porém, um sério obstáculo. Essa hipótese vai de encontro ao nosso atual conhecimento sobre a dependência da memória em relação ao funcionamento cerebral. É difícil ver como o conceito de reencarnação pode ser acomodado dentro da estrutura conceitual da ciência atual sem aceitar mente como uma realidade independente.

Os dois modelos explicativos opostos parecem irreconciliáveis sem uma radical mudança da visão científica atual. As evidências que sustentam a hipótese de reencarnação vêm crescendo nas últimas décadas. Até mesmo um renomado cético como o astrônomo Carl Sagan escreveu: "No momento em que escrevo, há três reivindicações no campo (paranormal) que, na minha opinião, merecem um estudo sério", o terceiro sendo "que crianças pequenas às vezes relatam detalhes de uma vida anterior que, após a verificação, se mostram precisos e que elas não poderiam ter esse conhecimento de nenhum outro modo que não pela reencarnação"14.

Esses casos podem ter grandes implicações para qualquer teoria da relação mente-corpo. A hipótese de reencarnação precisa assumir que mente e corpo são duas entidades separadas que só são combinados por um determinado período de tempo. 


\section{Referências}

1. Stevenson I. Reincarnation and biology. A contribution to the etiology of birthmarks and birth defects. Westport, Connecticut: Praeger; 1997.

2. Stevenson I. Children who remember previous lives. A question of reincarnation. Jefferson NC, editor: McFarland and Co.; 2001.

3. Haraldsson E. Children claiming past-life memories: four cases in Sri Lanka. J Sci Exploration. 1991;5:233-62.

4. Haraldsson E. Birthmarks and claims of previous life memories I. The case of Purnima Ekanayake. Journal of the Society for Psychical Research. 2000;64(858):16-25.

5. Haraldsson E. Birthmarks and claims of previous life memories II. The case of Chatura Karunaratne. Journal of the Society for Psychical Research. 2000;64(859):82-92.

6. Haraldsson E, Abu-Izzeddin M. Development of certainty about the correct deceased person in a case of the reincarnation type: the case of Nazih Al-Danaf. J Sci Exploration. 2002;16:363-80.

7. Haraldsson E, Abu-Izzeddin M. Three randomly selected Lebanese cases of children who claim memories of a previous life. Journal of the Society for Psychical Research. 2004;84(875):65-85.
8. Haraldsson E. Psychological comparison between ordinary children and those who claim previous-life memories. J Sci Exploration. 1997;11:32335.

9. Haraldsson E. Children who speak of past-life experiences: is there a psychological explanation? Psychol Psychother. 2003;76(Pt 1):55-67.

10. Haraldsson E, Fowler F, Periyannanpillai V. Psychological characteristics of children who speak of a previous life: a further field study in Sri Lanka. Transcult Psychiatry. 2000;37:525-44.

11. Mills A, Haraldsson E, Keil HHJ. Replication studies of cases suggestive of reincarnation by three independent investigators. J Am Soc Psych Res. 1994;88:207-19.

12. Tucker JR. Life before life. New York: St. Martin's Press; 2005.

13. Stevenson I. Cases of the reincarnation type. Charlottesville: University Press of Virginia; 1975-1983.

14. Sagan C. The demon-haunted world: Science as a candle in the dark New York: Random House; 1996. 